\title{
Multipotent CNS Stem Cells Are Present in the Adult Mammalian Spinal Cord and Ventricular Neuroaxis
}

\author{
Samuel Weiss, ${ }^{1}$ Christine Dunne, ${ }^{1}$ Jennifer Hewson, ${ }^{1}$ Cheryl Wohl, ${ }^{1}$ Matt Wheatley, ${ }^{1}$ Alan C. Peterson, ${ }^{2}$ and \\ Brent A. Reynolds 1 \\ ${ }^{1}$ Neuroscience Research Group, Departments of Anatomy and Pharmacology and Therapeutics, University of Calgary \\ Faculty of Medicine, Calgary, Alberta, Canada T2N 4N1, and 2Division of Experimental Medicine and Department of \\ Neurology and Neurosurgery, Faculty of Medicine, McGill University, Molecular Oncology Group, H5-35, Royal Victoria \\ Hospital, Montreal, Quebec, Canada H3A 1A1
}

\begin{abstract}
Neural stem cells in the lateral ventricles of the adult mouse CNS participate in repopulation of forebrain structures in vivo and are amenable to in vitro expansion by epidermal growth factor (EGF). There have been no reports of stem cells in more caudal brain regions or in the spinal cord of adult mammals. In this study we found that although ineffective alone, EGF and basic fibroblast growth factor (bFGF) cooperated to induce the proliferation, self-renewal, and expansion of neural stem cells isolated from the adult mouse thoracic spinal cord. The proliferating stem cells, in both primary culture and secondary expanded clones, formed spheres of undifferentiated cells that were induced to differentiate into neurons, astrocytes, and oligodendrocytes. Neural stem cells, whose proliferation was
\end{abstract}

dependent on EGF+bFGF, were also isolated from the lumbar/ sacral segment of the spinal cord as well as the third and fourth ventricles (but not adjacent brain parenchyma). Although all of the stem cells examined were similarly multipotent and expandable, quantitative analyses demonstrated that the lateral ventricles (EGF-dependent) and lumbar/sacral spinal cord (EGF+bFGF-dependent) yielded the greatest number of these cells. Thus, the spinal cord and the entire ventricular neuroaxis of the adult mammalian CNS contain multipotent stem cells, present at variable frequency and with unique in vitro activation requirements.

Key words: stem cells; spinal cord; ventricles; renewal; multipotent; epidermal growth factor; basic fibroblast growth factor
After formation of the neural tube, a period of prolonged histogenesis, which continues until shortly after birth, results in the formation of the mature CNS. In few instances (discussed below) does neuronal production continue into the adult. Moreover, the adult mammalian CNS shows virtually no capacity for neuronal replacement after injury or disease. Thus, it has been accepted that the adult CNS does not contain stem cells, those specialized cells that participate in cell replacement in tissues that require constant turnover, such as the skin and hematopoietic system (Hall and Watt, 1989; Potten and Loeffler, 1990).

Recently, a series of studies, fueled by evidence for mitotic activity in the subependyma of the forebrain lateral ventricles (Smart, 1961), have lead to the proposition that neural stem cells are indeed present in that region (for review, see Weiss et al., 1996). Morshead and van der Kooy (1992) showed that the subependyma comprised mixed populations of cells, some of which were mitotically active, and that some of the progeny underwent cell death. Subsequently, it was demonstrated that mitotically active cells within the subependyma, when explanted into culture, could generate neurons and glia (Lois and Alvarez-

\footnotetext{
Received May 10, 1996; revised Aug. 16, 1996; accepted Sept. 10, 1996.

This work was supported by the Medical Research Council of Canada (MRC) and the NeuroScience Network of the National Centres of Excellence. S.W. is an Alberta Heritage Foundation for Medical Research Scholar and an MRC Scientist. We thank Dr. Derek van der Kooy and Christopher Bjornson for critical reading of an earlier version of this manuscript.

Correspondence should be addressed to Dr. Samuel Weiss, Department of Anatomy, University of Calgary Faculty of Medicine, 3330 Hospital Drive NW, Calgary, Alberta, Canada T2N 4N1.

Dr. Reynolds' present address: NeuroSpheres Ltd., 83HM-3330 Hospital Drive NW, Calgary, Alberta, Canada T2N 4N1.

Copyright (C) 1996 Society for Neuroscience $0270-6474 / 96 / 167599-11 \$ 05.00 / 0$
}

Buylla, 1993) and that adult neuronal precursors in the subependyma migrated to the olfactory bulb to replace dead or dying granule neurons (Lois and Alvarez-Buylla, 1994). Thus, a process that had first been shown to take place in the neonatal brain (Luskin, 1993) persists into adulthood. Coupling these findings and our earlier observation that epidermal growth factor (EGF)responsive self-renewing cells isolated from the adult striatum could generate neurons and glia in vitro (Reynolds and Weiss, 1992), we asked whether these cells were located in the subependyma and were part of the mitotically active population in vivo. The use of high $\left[{ }^{3} \mathrm{H}\right]$ thymidine concentrations to kill cells that were rapidly turning over provided evidence for a relatively quiescent cell with identity to the in vitro EGF-responsive cell, whose presumptive role is to repopulate the subependyma (Morshead et al., 1994). These studies support the presence of multipotent stem cells in the mammalian forebrain that participate in repopulation of the subependyma and olfactory bulb.

Persistent neuronal and glial genesis also occurs within the dentate gyrus of the adult rodent hippocampus (Altman and Das, 1965; Bayer et al., 1982; Cameron et al., 1993), and in vitro studies demonstrate that basic fibroblast growth factor (bFGF) can support proliferation of adult hippocampal neuronal and glial progenitors (Palmer et al., 1995). The only other report of persistent turnover throughout the adult CNS is that of astroglia (Altman, 1963; Korr, 1980); however, it is unclear whether this turnover occurs in place or is the result of the migration of precursors from the ventricular zone. In this regard, however, there is little evidence for mitotic activity in other ventricles (Chauhan and Lewis, 1979) when compared with that of the subependyma. As opposed to the quiescent nature of the cerebral ventricles (other than the 
lateral ventricles), some mitotic activity has been reported in the adult spinal cord (Adrian and Walker, 1962; Kraus-Ruppert et al., 1975), including a small number of cells that line or are near the central canal (Adrian and Walker, 1962). Frisen and colleagues (1995) demonstrated increased mitotic activity after spinal cord laminectomy resulting in the generation of glia from nestinpositive cells. The authors suggest that these new glia arise from precursors that may be present close to or within the ependymal lining. Some previous studies (for review, see Bruni et al., 1985) have suggested that the ependyma may still contain cells with neuroepithelial potential. Ray and Gage (1994) have demonstrated that bFGF can stimulate embryonic spinal cord neuroblast proliferation; however, actions on adult cells have not been reported. Thus, in the present study we asked whether the adult spinal cord, when dissociated and plated in culture, could yield proliferating multipotent stem cells.

\section{MATERIALS AND METHODS}

Primary culture of adult brain tissue. Adult mice (male and female CD1, Charles River, St. Constant, Quebec, Canada) were killed by cervical dislocation. The brain and/or spinal cord were placed in $95 \% \mathrm{O}_{2} / 5 \% \mathrm{CO}_{2}$ oxygenated artificial cerebrospinal fluid [(aCSF) containing $124 \mathrm{~mm}$ $\mathrm{NaCl}, 5 \mathrm{~mm} \mathrm{KCl}, 1.3 \mathrm{~mm} \mathrm{MgCl}_{2}, 2 \mathrm{~mm} \mathrm{CaCl}_{2}, 26 \mathrm{~mm} \mathrm{NaHCO}_{3}$, D-glucose, and penicillin-streptomycin solution 1:25 (Life Technologies, Gaithersburg, MD), pH 7.35, $\sim 280 \mathrm{mOsm}$ ] for further dissection. The precise regions and their dissection are illustrated and described in Figure 7 and its legend, respectively. The tissue, regardless of origin, was cut into smaller pieces $\left(\sim 1 \mathrm{~mm}^{3}\right)$ and transferred into spinner flasks (Bellco Glass) with a magnetic stirrer filled with low $\mathrm{Ca}^{2}$, high $\mathrm{Mg}^{2+}$ aCSF (containing $124 \mathrm{~mm} \mathrm{NaCl}, 5 \mathrm{~mm} \mathrm{KCl}, 3.2 \mathrm{~mm} \mathrm{MgCl} 2,0.1 \mathrm{~mm} \mathrm{CaCl}, 26$ $\mathrm{mM} \mathrm{NaHCO}, 10 \mathrm{~mm}$ D-glucose, and penicillin-streptomycin $1: 25, \mathrm{pH}$ $7.35, \sim 280 \mathrm{mOsm})$, and an enzyme mixture $(1.33 \mathrm{mg} / \mathrm{ml}$ of trypsin, 0.67 $\mathrm{mg} / \mathrm{ml}$ of hyaluronidase, and $0.2 \mathrm{mg} / \mathrm{ml}$ of kynurenic acid). The stirring tissue suspension was aerated with $95 \% \mathrm{O}_{2} / 5 \% \mathrm{CO}_{2}$ at $32-35^{\circ} \mathrm{C}$ for $90 \mathrm{~min}$. After this enzymatic incubation period, the tissue was transferred to DMEM/F-12 (1:1; Life Technologies) medium containing $0.7 \mathrm{mg} / \mathrm{ml}$ of ovamucoid (Sigma, St. Louis, MO) and triturated mechanically with a fired-narrowed Pasteur pipette. The dissociated cell suspension was centrifuged at $400 \mathrm{rpm}$ for $5 \mathrm{~min}$, and the pellet was washed once and then plated $(5000-10,000$ viable cells $/ \mathrm{ml})$ in noncoated 6 -well ( $2 \mathrm{ml}$ volume $)$ Nunc tissue-culture dishes in media composed of DMEM/F-12 (1:1), including HEPES buffer $(5 \mathrm{mM})$, glucose $(0.6 \%)$, sodium bicarbonate (3 $\mathrm{mM})$, and glutamine $(2 \mathrm{mM})$. A defined hormone and salt mixture composed of insulin $(25 \mu \mathrm{g} / \mathrm{ml})$, transferrin $(100 \mu \mathrm{g} / \mathrm{ml})$, progesterone $(20$ $\mathrm{nM})$, putrescine $(60 \mu \mathrm{M})$, and sodium selenite $(30 \mathrm{nM})$ was used in place of serum. To the above medium, EGF or bFGF (human recombinant; Chiron Corporation, Emeryville, CA) or both were added at $20 \mathrm{ng} / \mathrm{ml}$. Primary stem cell proliferation was detected after $7-8 \mathrm{~d}$ in vitro and characterized by the formation of spheres of undifferentiated cells (Reynolds and Weiss, 1992).

Dissociation and perpetuation of EGF+bFGF-generated spheres for clonal analyses. (Schematic representation is given in Fig. 5). To test whether the EGF+bFGF-responsive cell exhibits self-maintenance, two different experiments were carried out: (pathway 2 of Fig. 5) plating of single cells derived from primary EGF+bFGF-generated spheres into 96-well plates and (pathway 3 of Fig. 5) dissociation of single EGF+bFGF-generated spheres. For plating single cells, a single primary EGF+bFGF-generated sphere was collected after $8 \mathrm{~d}$ in vitro, mechanically dissociated, and serially diluted to yield approximately one to two cells per $10 \mu \mathrm{l}$ aliquot. A $10 \mu \mathrm{l}$ aliquot was added to each well of a 96-well plate containing $200 \mu \mathrm{l}$ of EGF+bFGF-containing medium. Plates were scored $24 \mathrm{hr}$ later. All wells that contained one viable cell were marked, and these wells were rescored $8 \mathrm{~d}$ later for the presence of spheres. Single spheres were dissociated by taking a $10-100 \mu \mathrm{l}$ aliquot of $8 \mathrm{~d}$ in vitro EGF+bFGF-generated spheres and transferring the spheres into $\mathrm{Nu}-$ cleon $35 \mathrm{~mm}$ tissue-culture dishes with EGF+bFGF-containing medium. Under sterile conditions, single spheres were transferred to $500 \mu \mathrm{lEp}$ pendorf tubes containing $200 \mu \mathrm{l}$ of medium, triturated 20-40 times, and plated into a 96-well plate. The plates were scored $8 \mathrm{~d}$ later for the number of spheres derived from a single sphere.

Differentiation of EGF+bFGF-generated spheres. Eight to ten days after the primary culture or secondary culture $(21 \mathrm{~d}$ for single-cellderived spheres), spheres were removed with a pipette, spun down at $400 \mathrm{rpm}$, and resuspended in EGF+bFGF-containing medium. The spheres were differentiated in single-sphere cultures (pathway 1 of Fig. $5)$. Single isolated spheres were plated on poly-L-ornithine-coated (15 $\mu \mathrm{g} / \mathrm{ml})$ glass coverslips in individual wells of 24-well Nunclon (1.0 $\mathrm{ml} /$ well) culture dishes in DMEM/F-12 medium with the hormone and salt mixture and EGF+bFGF. Medium was not changed for the rest of the experiment. Coverslips were processed 21-25 d later for indirect immunocytochemistry.

Antibodies. Rabbit antiserum to nestin (Rat 401; 1:1500) was a gift from Drs. M. Marvin and R. McKay; a mouse monoclonal antibody against the $168 \mathrm{kDa}$ neurofilament protein (clone RMO 270; 1:50) was generously supplied by Dr. V. Lee; rabbit antiserum to glial fibrillary acidic protein (GFAP; 1:1000) was a gift from Dr. L. Eng; mouse monoclonal antibody (IgM) to O4 (1:20) was a gift from Dr. M. Schachner; mouse monoclonal antibody to MAP-2 was from Boehringer Mannheim (Indianapolis, IN); and mouse monoclonal antibody to $\beta$-tubulin (Type III; $1: 1000$ ) was from Sigma. Rabbit polyclonal antisera to Substance P (1:1000) was from Incstar, and to GABA (1:3000) was from Chemicon. Fluoresceinconjugated and rhodamine-conjugated affinipure goat antibody to mouse $\mathrm{IgG}$, rhodamine-conjugated affinipure goat antibody to rabbit $\mathrm{IgG}$, and AMCA-conjugated affinipure goat antibody to mouse IgM were obtained from Jackson ImmunoResearch (West Grove, PA).

Immunocytochemistry. Indirect immunocytochemistry was carried out with spheres attached to glass coverslips, either immediately after plating (for nestin) or after 21-25 d in vitro (for triple-labeling and for neuronal phenotypes). Coverslips were fixed in $4 \%$ paraformaldehyde (in PBS, $\mathrm{pH}$ 7.2) for $30 \mathrm{~min}$, followed by three (10 min each) washes in PBS, $\mathrm{pH}$ 7.2. Nestin, Substance P, or GABA antisera were diluted in PBS $/ 10 \%$ normal goat serum $/ 0.3 \%$ Triton X-100 and incubated with the coverslips for $2 \mathrm{hr}$ at $37^{\circ} \mathrm{C}$. Coverslips were washed three times $(10 \mathrm{~min}$ each $)$ in PBS and incubated in appropriate secondary antibodies $(1: 100)$ for $30 \mathrm{~min}$ at $37^{\circ} \mathrm{C}$. For the triple-labeling experiments, cells were permeabilized briefly for 5 min $(0.3 \%$ Triton X-100/PBS) after fixation, followed by the addition of the neuron-specific monoclonal antibody to either MAP-2 or NFM (IgG) together with polyclonal antiserum to GFAP. Appropriate secondary antibodies were added, followed by incubation with monoclonal antibody to $\mathrm{O} 4(\mathrm{IgM})$, and a goat anti-mouse $\operatorname{IgM}$ specific secondary (AMCA) was used to visualize the $\mathrm{O} 4$ antibody. It is noteworthy that the permeabilization procedure renders the normal uniform staining of the extracellular antigen O4 (Reynolds and Weiss, 1993) to a punctate representation (Reynolds and Weiss, 1996; this study). Coverslips received three (10 min each) washes in PBS and were rinsed with water, placed on glass slides, and coverslipped with Fluorsave as the mounting medium. Fluorescence was detected and photographed on a Zeiss photomicroscope with Kodak T-Max 400 film.

\section{RESULTS}

\section{Multipotent cells that respond to EGF+bFGF can be isolated from the adult thoracic spinal cord}

In previous studies (Reynolds and Weiss, 1992; Morshead et al., 1994), we found that EGF induced the proliferation of multipotent, self-renewing, and expandable stem cells that were isolated from the adult subependymal cell layer of the forebrain. On proliferation, these cells formed spheres of undifferentiated cells that could generate neurons and glia. Thus, we asked whether similar cells could be isolated from the adult spinal cord. Adult thoracic spinal cord was dissected, enzymatically dissociated, and plated in the presence of EGF $(20 \mathrm{ng} / \mathrm{ml})$ or bFGF $(20 \mathrm{ng} / \mathrm{ml})$. After $8 \mathrm{~d}$ in vitro, cells cultured in the presence of EGF showed no evidence of the characteristic spheres of proliferating cells. In the presence of bFGF, very small clusters of cells were found; however, these clusters could not renew (only $15 \%$ produced one secondary sphere) or expand (none produced more than one secondary sphere). When EGF and bFGF were combined, however, large self-renewing and expandable spheres were generated (Fig. 1). Quantitative analysis showed that $8.6 \pm 3.4$ spheres/5000 viable cells were generated. These spheres were similar to those isolated from the subependymal cell layer of the forebrain in that 

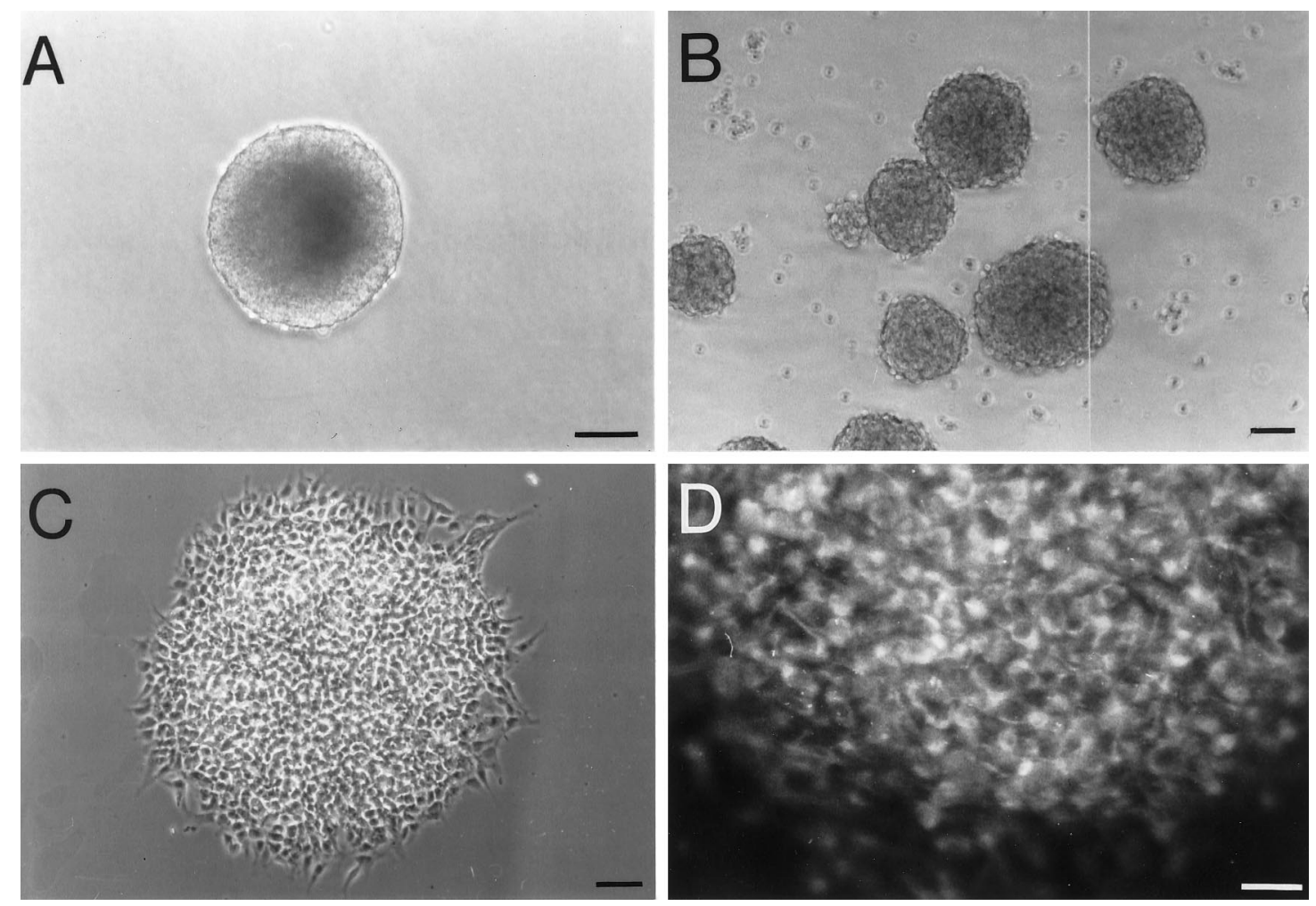

Figure 1. Characteristics of spheres generated from isolated cells of the adult thoracic spinal cord. $A, B$, An example of a single sphere generated from the adult thoracic cord $(A)$, which was dissociated into single cells that yielded close to 300 spheres 1 week later, some of which are illustrated in $B$. $C$, $D$, Spheres generated from the adult thoracic spinal cord contained no differentiated cells; however, virtually all cells within these spheres $(C)$ expressed nestin $(D)$, an intermediate filament characteristic of undifferentiated neuroepithelial cells. Scale bars: $A, 100 \mu \mathrm{m} ; B, 50 \mu \mathrm{m} ; C, 50 \mu \mathrm{m} ; D, 30 \mu \mathrm{m}$.

a single sphere (Fig. 1A) could be dissociated and replated under identical conditions to yield more than one of itself (Fig. 1B). Quantitative analysis showed that on average a single primary sphere yielded $127 \pm 14$ secondary spheres. Also similar to that observed in forebrain-derived cultures, both primary and secondary spheres contained undifferentiated cells, as determined by the expression of nestin immunoreactivity (Fig. 1C,D) and the absence of antigens characteristic of differentiated neural cells (data not shown).

We next asked whether the EGF+bFGF-generated spheres could yield differentiated neural cells when plated on a poly-Lornithine substrate. Single spheres were transferred onto polycation-coated glass coverslips in the continued presence of $\mathrm{EGF}+\mathrm{bFGF}$ and cultured for an additional $21 \mathrm{~d}$ in vitro. The single-sphere cultures were then fixed and processed for triplelabel immunocytochemistry. Antibodies to MAP-2 or NFM were used to identify neurons, whereas antiserum to GFAP and antibody to $\mathrm{O} 4$ were used to identify astrocytes and oligodendrocytes, respectively. When MAP-2 was the antigen examined for neuronal identity, every sphere was found to contain the three principal neural cell types (106/106 spheres from 23 separate primary cultures). An example is illustrated in Figure 2. As outlined in Materials and Methods, permeabilization renders the normally uniform staining with $\mathrm{O} 4$ to a punctate representation. This is illustrated in Figure 3, whereby an example of a nonpermeabilized O4-immunoreactive cell (Fig. $3 A$; typical oligodendrocyte morphology) is contrasted with a permeabilized O4-immunoreactive cell (Fig. 3B,C; selective, punctate staining) from a sister culture. Without such permeabilization, we could not clearly detect or distinguish neurons from the other two cell types when the three were examined simultaneously. Under these experimental conditions, $1.0 \pm 0.2 \%$ of total cells were identified as neurons, $0.3 \pm$ $0.1 \%$ as astrocytes, and $0.7 \pm 0.2 \%$ as oligodendrocytes $(n=20)$. The majority of the remaining cells was immunoreactive for nestin (data not shown).

When NFM was the neuronal antigen, 13 of 15 spheres (from three separate primary cultures) examined showed the three cell types. An example of NFM immunoreactivity illustrated in Figure $4 B$ shows the thin fibers that displayed immunoreactivity; cell bodies were rarely labeled. We next examined the presence of distinct neuronal phenotypes in single-sphere cultures derived from the thoracic spinal cord. Every sphere examined (37/37 spheres from six separate primary cultures) contained GABAergic neurons (example given in Fig. $4 E, F$ ). Neurons that were immunoreactive for substance $\mathrm{P}$ were also found (data not shown). Other neurotransmitter phenotypes, e.g., serotonin, tyrosine hydroxylase, and choline acetyltransferase, were not detected in these single-sphere cultures. Thus, the neurotransmitter phenotype of thoracic spheres was similar to that of both embryonic (Reynolds et al., 1992; Ahmed et al., 1995) and adult (Reynolds and Weiss, 1992) EGF-generated forebrain spheres.

\section{Clonal analysis demonstrates that the thoracic spinal cord cells that proliferate in response to EGF+bFGF are neural stem cells}

Recently, we and others have developed criteria for demonstrating that a proliferating adult CNS cell is a stem cell (Gritti et al., 1996; Reynolds and Weiss, 1996). This involves examining the expansion of secondary clones derived from primary proliferating cells. These criteria are illustrated schematically in Figure 5. In 

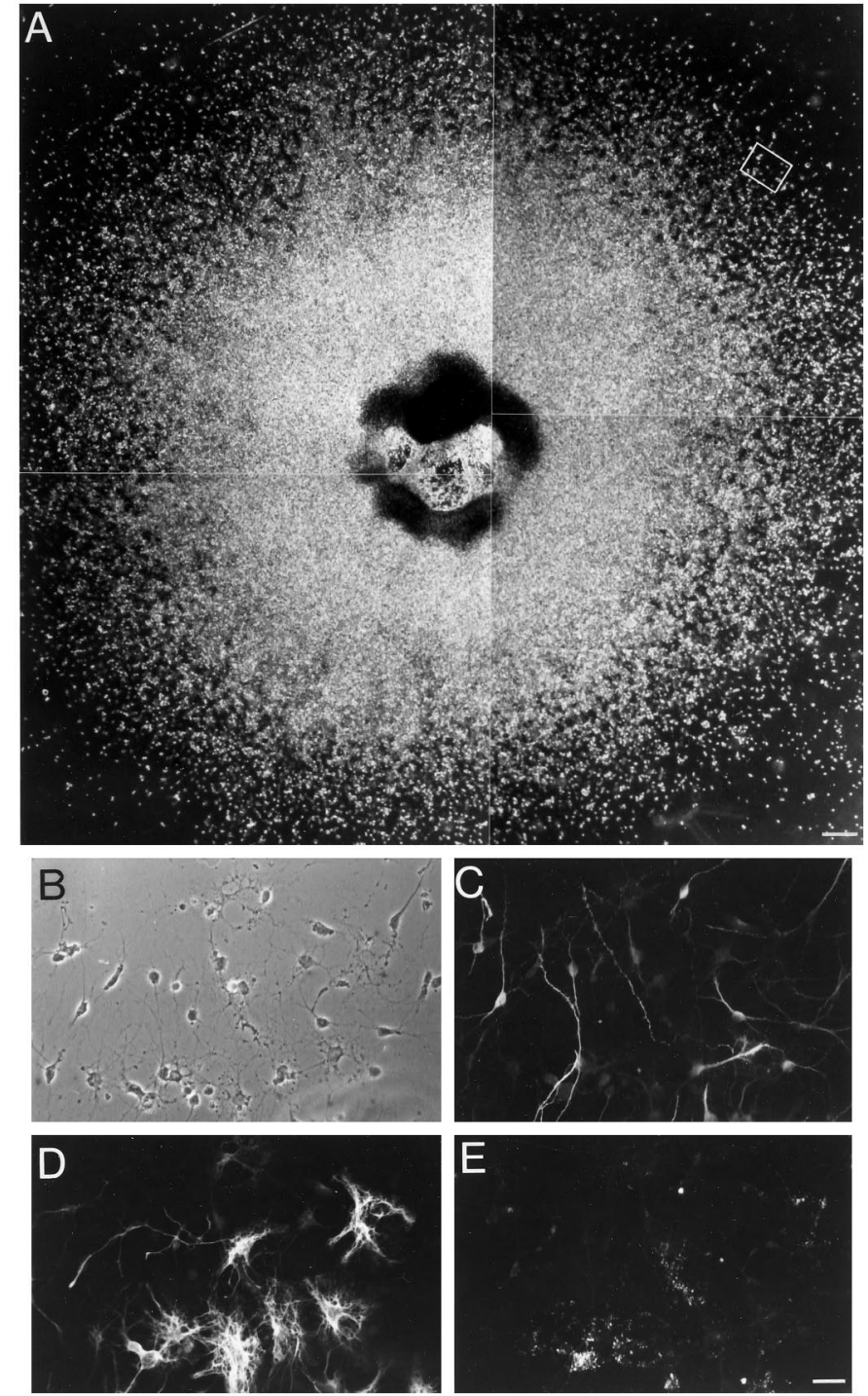

Figure 2. Single spheres derived from the adult thoracic spinal cord yielded neurons, astrocytes, and oligodendrocytes. $A$, A single, isolated sphere was transferred onto poly-L-ornithine-coated glass coverslips, cultured for 3 weeks in the presence of EGF+bFGF, fixed, and processed for indirect immunocytochemistry. $B-E$, Triple-label immunocytochemistry of the sphere in $A$, illustrating the cells within the box $(B)$, shows $(C)$ MAP-2-, $(D)$ GFAP-, and (E) O4-immunoreactive cells, with the morphology of neurons, astrocytes, and oligodendrocytes, respectively. Scale bars: $A, 200 \mu \mathrm{m} ; B-E$ (shown in $E$ ), $20 \mu \mathrm{m}$.

this scheme, a neural stem cell can self-renew and expand, and the progeny of the secondary expanded clones should exhibit the same phenotype as the primary cells. Thus, we tested the spheres derived from thoracic spinal cord, in the presence of EGF+bFGF, to determine whether they would satisfy these criteria. First, we showed that single cells, derived from single primary spheres, could proliferate and form spheres that generate neurons, astrocytes, and oligodendrocytes (Fig. 6). Next, we compared the phenotype potential of primary spheres and secondary spheres derived from single-cell culture or total single-sphere dissociations. The results are summarized in Table 1. When primary spheres were examined for their ability to generated neurons, astrocytes, and oligodendrocytes, all were found to be tripotential. This was also true for secondary spheres, both those generated
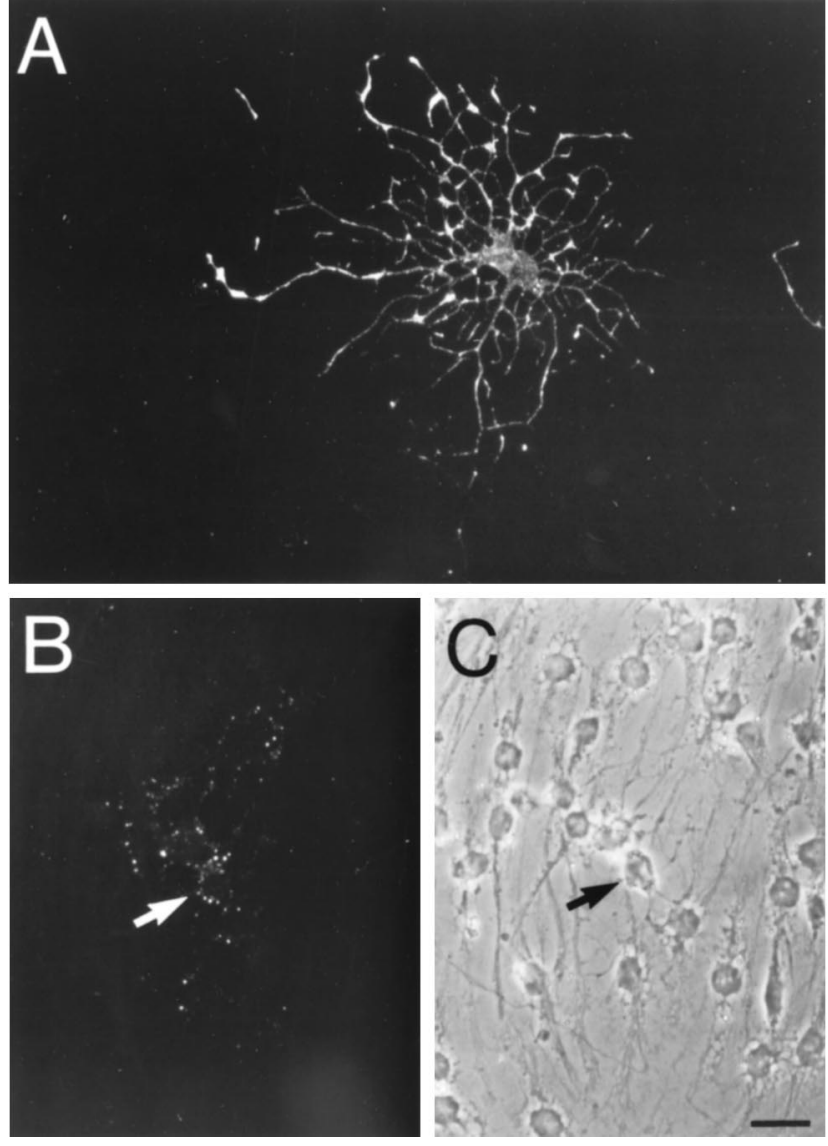

Figure 3. Examples of O4-immunoreactive cells in plated adult thoracic spinal cord spheres, with and without permeabilization. $A$, An O4immunoreactive cell in a fixed, but nonpermeabilized, single thoracic sphere culture, demonstrating typical oligodendrocyte morphology. $B, C$, In a fixed and permeabilized sister culture, a single oligodendrocyte (arrow) is specifically stained in a punctate fashion with the $\mathrm{O} 4$ antibody. Scale bar, $20 \mu \mathrm{m}$.

through single-cell culture (11/11 spheres, six primary cultures) and those generated through single-sphere dissociation (79/79 spheres, 15 primary cultures). The ability to self-renew, expand, and maintain the potential to produce the three major cell types supports the contention that the cells from the thoracic spinal cord that proliferate in response to EGF+bFGF are stem cells.

\section{Neural stem cells are present in other regions of the spinal cord and in the third and fourth ventricles}

The presence of self-renewing stem cells in the thoracic spinal cord, whose proliferation depended on the combined actions of EGF and bFGF, prompted us to examine whether similar cells reside in other spinal cord regions as well as line other ventricles. We hypothesized that such cells would line ventricles, given previous findings that in the forebrain neural stem cells could be isolated only from tissue that contained the subependymal cell layer (Morshead et al., 1994). Thus, we compared the frequency and growth factor dependence of putative neural stem cells, isolated from the lateral, third, and fourth ventricles (with adjacent parenchyma as a suspected negative control) and from the thoracic and lumbar/sacral segments of the spinal cord. Separating central canal from adjacent spinal cord tissue was technically not possible. The precise dissection is outlined in Figure 7 . We plated equivalent numbers of cells from the various regions and 

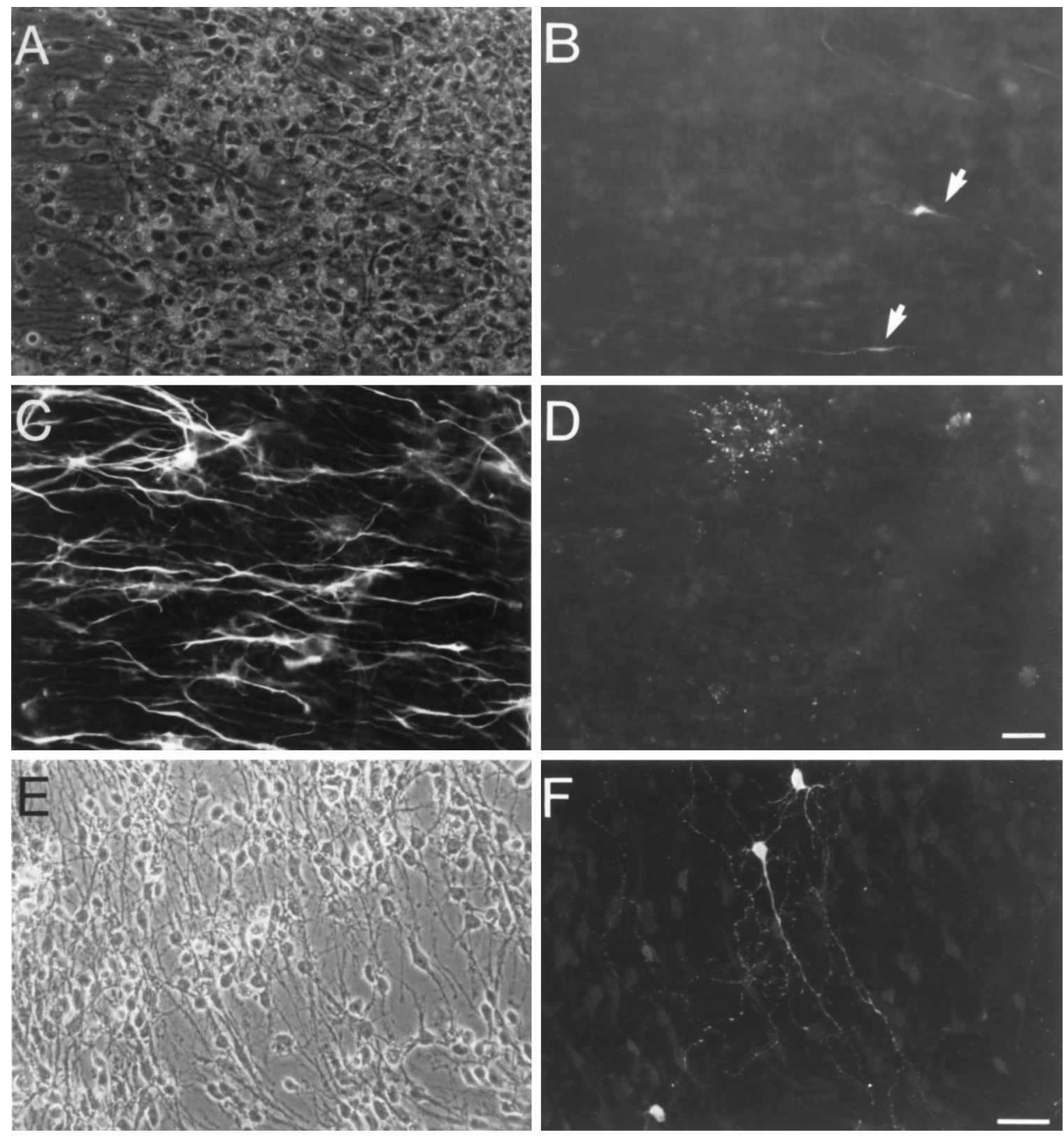

Figure 4. Further characterization of the phenotypes of cells derived from stem cells of the thoracic spinal cord. $A-D$, Triple-label immunocytochemistry of single spheres derived from the thoracic spinal cord, after 3 weeks of plating on poly-L-ornithine. $A$, Representative field shows $(B)$ neurofilament $M$ $(160 \mathrm{kDa}$; arrows), (C) GFAP, and $(D) \mathrm{O} 4$ immunoreactivity, characteristic of neurons, astrocytes, and oligodendrocytes, respectively. $E$, $F$, The principal neuronal phenotype detected, after 3 weeks of plating on poly-L-ornithine, was GABA. Indirect immunocytochemistry of a representative field $(E)$ shows cells with neuronal morphology that were GABA-immunoreactive $(F)$. Scale bars: $A-D$ (shown in $D$ ), $20 \mu \mathrm{m} ; E, F$ (shown in $F$ ), $30 \mu \mathrm{m}$.

counted the numbers of spheres generated per 5000 viable cells plated, in the presence of EGF or bFGF alone or together. Only those spheres that could be subcloned (as described above and illustrated later in Table 3) were counted. Our results, shown in Table 2, suggest that stem cells with different growth requirements and frequencies are present throughout the entire ventricular neuroaxis. First, only cells within the lateral ventricles yielded self-renewing and expandable spheres in response to EGF (26.7 \pm 3.7 spheres/5000 cells). An identical number $(26.8 \pm 4.5)$ was found when EGF and bFGF were combined; however, in both of the other ventricular regions tested, neither EGF nor bFGF alone was sufficient to induce the formation of self-renewing, expandable spheres. Moreover, there was a decreasing frequency from the lateral to the third and then fourth ventricle. The cultures of the third ventricle differed from all other regions in one regard: spheres took twice as long to form (14-16 d vs 7-8 d for all other regions). In all cases, no spheres were generated when the adjacent parenchyma (as illustrated in Fig. 7) was cultured under identical conditions.

When comparing the thoracic and lumbar/sacral regions of the spinal cord, where again self-renewing, expandable spheres were generated only with $\mathrm{EGF}+\mathrm{bFGF}$, we found that the greatest number of spheres was generated from cells of the lumbar/sacral cord (32.6 \pm 3.2$)$. This represented an approximately fourfold greater frequency when compared with the thoracic cord. Moreover, this represented the greatest frequency in relation to all 


\section{Primary Dissociated Adult Tissue}

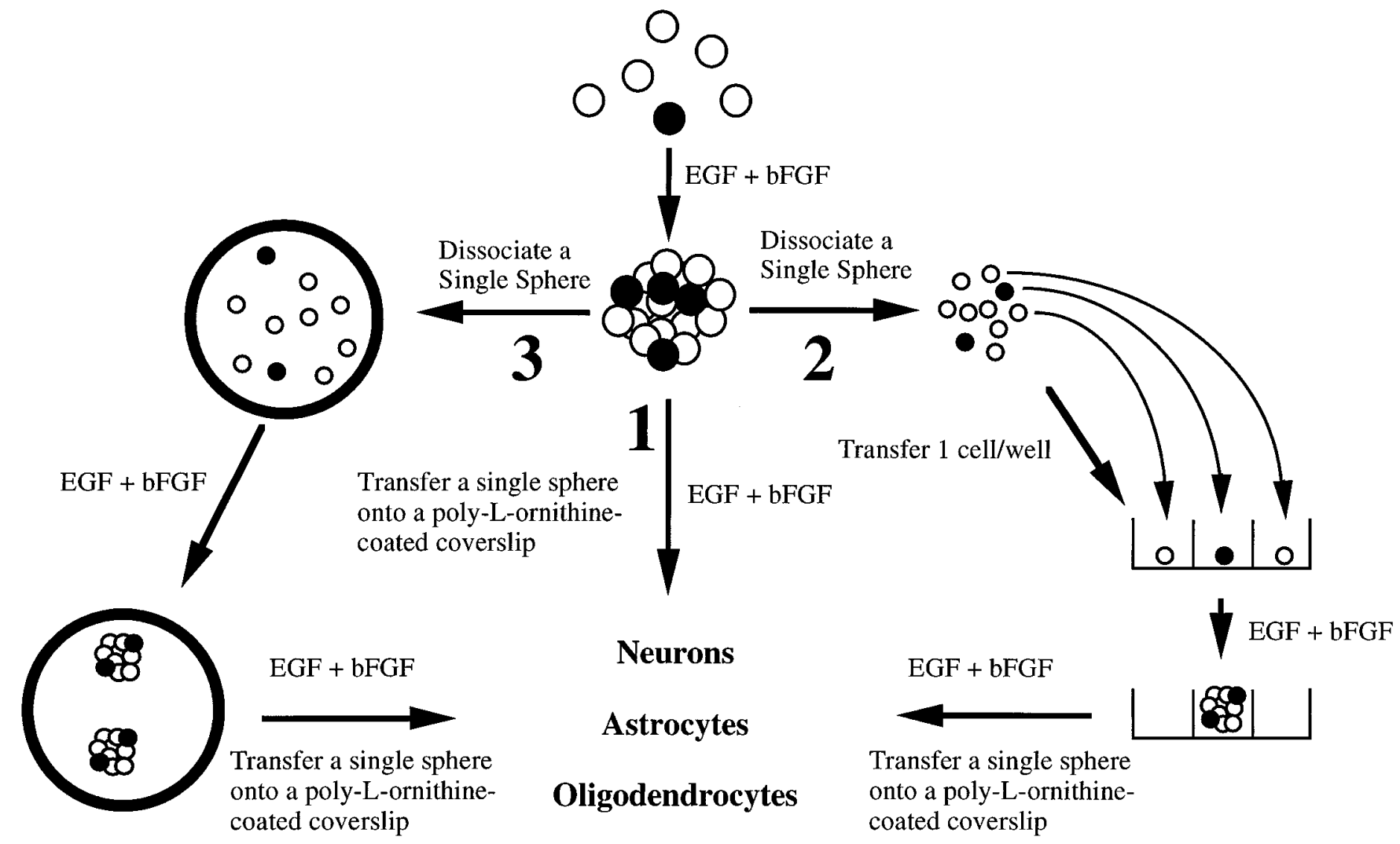

Figure 5. Schematic representation of approaches used to establish adult spinal cord stem cell proliferation, self-renewal and expansion, and production of neurons, astrocytes, and oligodendrocytes. The experimental approaches to demonstrating self-renewal and expansion of stem cells in response to EGF + bFGF are shown. When primary, dissociated adult cells are exposed to EGF+bFGF, spheres of undifferentiated cells are generated. (1) Differentiation of single primary spheres results in the production of neurons, astrocytes, and oligodendrocytes. (2) Dissociation of single primary spheres into single cells, which are plated after serial dilution as $1 \mathrm{cell} /$ well, generates clonally derived secondary spheres. Differentiation of single secondary spheres results in the production of neurons, astrocytes, and oligodendrocytes. (3) Dissociation of single primary spheres into single cells, all of which are plated into one well, results in more than one secondary sphere. Once again, differentiation of these single secondary spheres results in the production of neurons, astrocytes, and oligodendrocytes.

regions tested. Given the differing tissue dissections, however, comparisons with the ventricles would be difficult. Furthermore, it may be argued that with differing thicknesses/enlargements of the spinal cord, even comparisons between the segments may be misleading. Thus, we compared the frequency of EGF+bFGFgenerated spheres from cervical, thoracic, or lumbar/sacral spinal cord, this time normalizing for length of spinal cord. Our findings, shown in Figure 8, confirm the results given in Table 2. First, the comparison between thoracic and lumbar/sacral cord showed a three- to fourfold greater frequency of spheres in the latter regions. Furthermore, the frequency of spheres in the cervical cord (not previously examined) was the lowest of all of the spinal cord regions.

Although in all previous studies the formation of spheres was generally indicative of it being derived from stem cells, e.g., tripotential cells with self-renewal and expandable properties, we wished to confirm this to be the case for all of the regions examined. Thus, we compared the ability of spheres generated by EGF+bFGF, from the five regions examined, to self-renew/ expand and generate the three cell types. The results are shown in Table 3. Primary ( $n=9-23$ individual cultures) and secondary ( $n=4-15$ individual cultures) spheres were examined in the manner illustrated in pathways 1 and 3 of Figure 5. All primary spheres, regardless of region of origin, displayed an impressive ability to expand, yielding $\sim 79-127$ secondary spheres. The differences between regions were not statistically significant. Furthermore, in virtually all cases (430/433 individual spheres), neurons, astrocytes, and oligodendrocytes were generated in primary and secondary spheres. The three secondary spheres of the third ventricle contained neurons and astrocytes only. Therefore, using the criteria established above for embryonic cells that generated spheres (Reynolds and Weiss, 1996) and for thoracic spheres (Figs. 1-5, Table 1), it is reasonable to conclude that the spheres generated from all of the ventricles and spinal cord regions in response to EGF + bFGF are derived from multipotential, self-renewing stem cells.

\section{DISCUSSION}

The results of this study suggest that multipotent stem cells are present in the adult spinal cord and throughout the entire ventricular neuroaxis. Although stem cells isolated from the forebrain subependymal zone proliferate and expand in response to EGF alone (Reynolds and Weiss, 1992; Morshead et al., 1994), the stem cells of the third and fourth ventricles and spinal cord require the combined actions of EGF and bFGF. All of these stem 

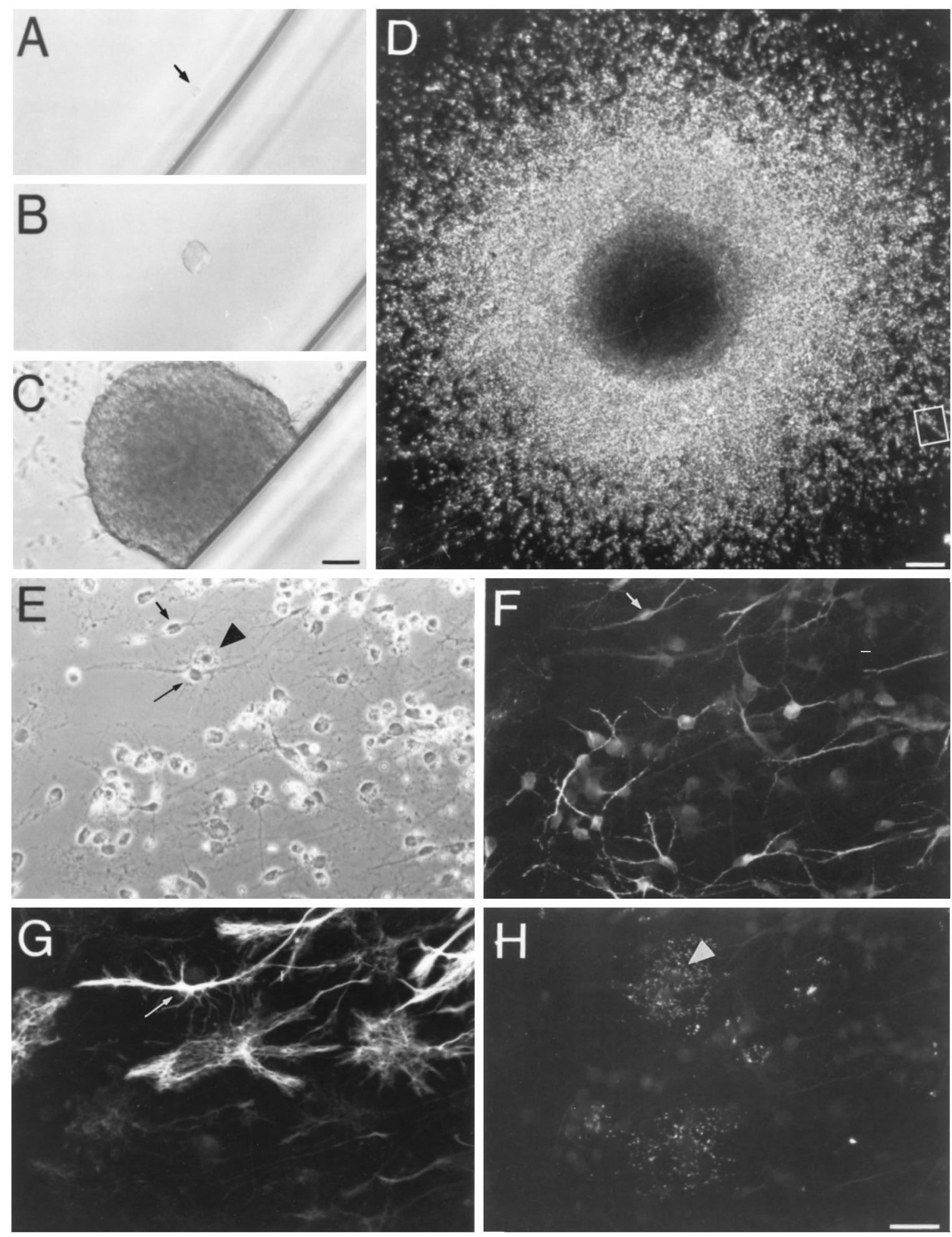

Figure 6. Primary spheres from the adult thoracic spinal cord give rise to clonally derived, multipotent secondary spheres. $A-H$, Multipotent secondary spheres are derived from a single cell. A single cell (arrow) dissociated from a primary sphere $(A)$ after $24 \mathrm{hr}$. After $5 \mathrm{~d}$ in vitro (B), the cell has begun to proliferate and has formed a large sphere after $14 \mathrm{~d}$ in vitro $(C)$. The sphere was transferred to a glass coverslip and cultured in the presence of EGF+bFGF. After 3 weeks $(D)$, the sphere was processed for indirect immunocytochemistry. The box designates the field $(E)$ that, through triple-labeling for MAP-2, GFAP, and O4 immunoreactivities, revealed the presence of neurons $(F$, short arrow), astrocytes $(G$, long arrow), and oligodendrocytes $(H$, arrowhead), respectively. Scale bars: $A-C$ (shown in $C$ ), $50 \mu \mathrm{m} ; D, 140 \mu \mathrm{m} ; E-H$ (shown in $H$ ), $30 \mu \mathrm{m}$.

cells share two hallmark properties: self-renewal/expansion and multipotency, as defined by the production of neurons, astrocytes, and oligodendrocytes by single stem cells (Gritti et al., 1996;
Reynolds and Weiss, 1996; Weiss et al., 1996). Taken together with previous studies of adult neural stem cells, however, these findings suggest that heterogeneity likely exists between (1) pri- 
Table 1. Multipotency of primary and renewed adult thoracic spinal cord stem cell-derived spheres

\begin{tabular}{lll} 
Experimental protocol & $\begin{array}{l}\text { Number of } \\
\text { independent } \\
\text { primary cultures }\end{array}$ & $\begin{array}{l}\text { Frequency of spheres } \\
\text { containing neurons, } \\
\text { astrocytes, and oligo- } \\
\text { dendrocytes }\end{array}$ \\
\hline Primary culture & 23 & $106 / 106$ \\
Single cell culture & 6 & $11 / 11$ \\
Single sphere dissociation & 15 & $79 / 79$
\end{tabular}

The experimental protocols correspond to those outlined schematically in Figure 5. Indirect immunocytochemistry for the three neural antigens is described in Materials and Methods.

mary stem cells (those removed from the brain) and the secondary stem cells they produce in culture and (2) stem cells in different ventricular regions, which may be related to their origin and/or functional roles in vivo.

A noteworthy finding in this study was the combined actions of EGF and bFGF in inducing proliferation of stem cells from the

A

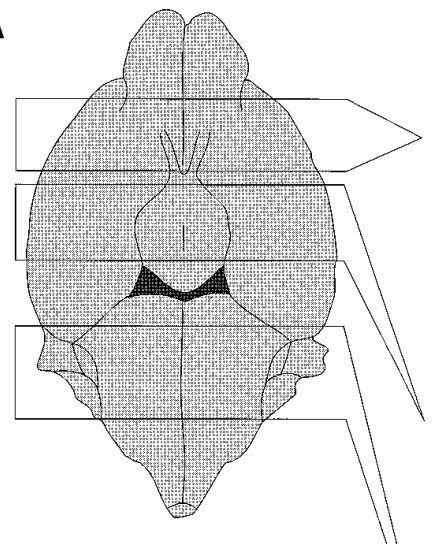

$\mathbf{E}$

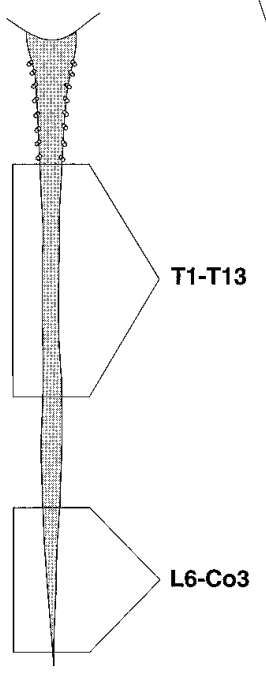

Figure 7. Regions of the adult CNS examined for the presence of growth factor-responsive stem cells. $A-D$, Ventral view of the adult mouse brain $(A)$, illustrating the coronal sectioned regions that were used to dissect lateral ventricle $(B)$, third ventricle $(C)$, and fourth ventricle $(D)$. Dark lines illustrate the regions considered ventricular, whereas stippled lines illustrate nonventricular regions of the same thick section. $E$, Adult mouse spinal cord, illustrating the regions dissected as thoracic (T1-T13) and lumbar/sacral (L6-Co3). As detailed in Results, stem cells were isolated from all ventricular regions examined but not from the adjacent parenchyma. Scale bar: each graduation is $1 \mathrm{~mm}$.
Table 2. Frequency and growth factor dependence of primary multipotent stem cell-derived spheres

Numbers of self-renewing, expandable spheres $/ 5000$ cells plated (mean \pm SEM)

\begin{tabular}{lllc}
\cline { 2 - 4 } Brain region & EGF & bFGF & EGF + bFGF \\
\hline Lateral ventricle & $26.7 \pm 3.7$ & - & $26.8 \pm 4.5$ \\
Third ventricle & - & - & $6.1 \pm 1.4^{a}$ \\
Fourth ventricle & - & - & $1.0 \pm 0.3$ \\
Thoracic cord & - & - & $8.6 \pm 3.4$ \\
Lumbar/sacral cord & - & - & $32.6 \pm 3.2$ \\
\hline
\end{tabular}

The brain regions indicated are those shown schematically in Figure 7. The data are the mean \pm SEM of spheres formed after $8 \mathrm{~d}$ in culture in at least four independent culture preparations, each condition performed in duplicate. Basic FGF was tested in the absence of added heparin [see Discussion and Gritti et al. (1996)].

${ }^{a}$ Counted after $14-16 \mathrm{~d}$.

spinal cord and third and fourth ventricles. Basic FGF has been reported to cooperate with other signals in allowing the long-term renewal of both pluripotential embryonic stem cells (Matsui et al., 1992) and O-2A glial progenitor cells (Bogler et al., 1990), and thus the cooperative nature of the response is not unusual. Our result, however, is in contrast to previous reports of EGF (Reynolds and Weiss, 1992) and bFGF (Gritti et al., 1996) individually as mitogens for subependymal/forebrain stem cells. Two questions arise immediately. First, why was bFGF reported to be ineffective in the first report (Reynolds and Weiss, 1992) of adult forebrain stem cells? Second, what can one conclude/propose regarding the in vitro actions of bFGF and/or EGF on adult spinal cord stem cells? The first question can be answered by comparing findings reported in this study for thoracic spinal cord stem cells with those of the lateral ventricle/forebrain (Reynolds and Weiss, 1992; Gritti et al., 1996). In the cultures of thoracic spinal cord, although EGF alone does not produce any spheres, bFGF alone will produce very small spheres. These bFGF spheres can be dissociated; however, they will never produce more than one secondary sphere, and only $15 \%$ of the time do they actually

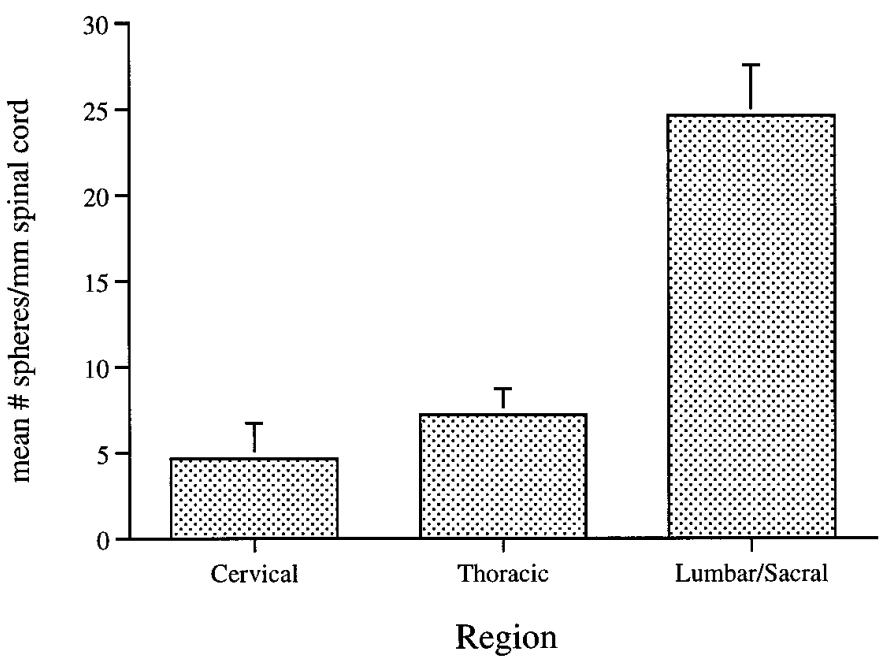

Figure 8. The in vitro generation of spheres derived from isolated cells of the adult spinal cord is greatest in the Lumbar/Sacral segment. The number of spheres generated in the presence of EGF+bFGF in vitro was determined for the three regions of the spinal cord indicated and was normalized to the length of spinal cord tissue dissected. The data represent the mean \pm SEM of duplicate determinations in six independent culture preparations. 
Table 3. Expansion and multipotency of growth factor-generated spheres derived from various brain regions

\begin{tabular}{|c|c|c|c|c|}
\hline Brain region & $\begin{array}{l}\text { No. } 2^{\circ} \text { spheres } \\
(\text { mean } \pm \text { SEM })\end{array}$ & No. of cultures & No. of spheres & No. $\mathrm{N}+\mathrm{A}+\mathrm{O}$ \\
\hline \multirow[t]{2}{*}{ Lateral ventricle } & $79 \pm 20$ & $1^{\circ} 9$ & 37 & 37 \\
\hline & & $2^{\circ} \quad 4$ & 9 & 9 \\
\hline \multirow[t]{2}{*}{ Third ventricle } & $84 \pm 21$ & $1^{\circ} 10$ & 33 & 33 \\
\hline & & $2^{\circ} 6$ & 33 & $30^{a}$ \\
\hline \multirow[t]{2}{*}{ Fourth ventricle } & $107 \pm 22$ & $1^{\circ} 12$ & 37 & 37 \\
\hline & & $2^{\circ} 9$ & 54 & 54 \\
\hline \multirow[t]{2}{*}{ Thoracic cord } & $127 \pm 14$ & $1^{\circ} 23$ & 106 & 106 \\
\hline & & $2^{\circ} 15$ & 79 & 79 \\
\hline \multirow[t]{2}{*}{ Lumbar/sacral cord } & $110 \pm 11$ & $1^{\circ} 9$ & 34 & 34 \\
\hline & & $2^{\circ} \quad 5$ & 11 & 11 \\
\hline
\end{tabular}

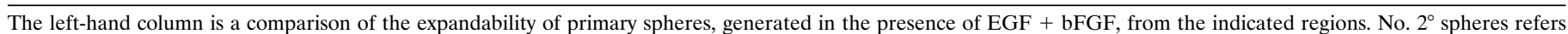

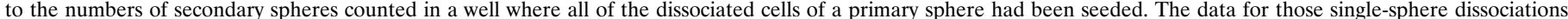

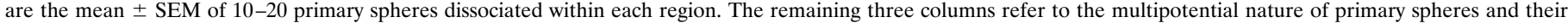

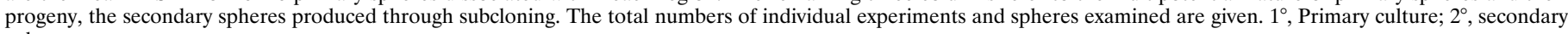
culture.

${ }^{a}$ Three spheres contained only neurons and astrocytes. $\mathrm{N}+\mathrm{A}+\mathrm{O}$, Neurons + astrocytes + oligodendrocytes.

renew themselves. We found that forebrain stem cells responded in a virtually identical fashion to bFGF alone (J. Hewson and S. Weiss, unpublished observations). Gritti et al. (1996) added heparin to their cultures of forebrain stem cells, and the actions of bFGF changed dramatically, resulting in the production of larger spheres with the potential to expand. The lack of this cofactor serves to explain why we reported that bFGF did not mimic EGF in inducing proliferation and self-renewal/expansion of stem cells in our early forebrain study (Reynolds and Weiss, 1992).

The second and perhaps more intriguing question, regarding the respective roles/actions of EGF versus bFGF in neural stem cell proliferation, points to differences between primary stem cells and their progeny, the secondary stem cells produced in culture. After this study reached completion, we read the study of Gritti et al. (1996), which reported successful subcloning of $\mathrm{bFGF}+$ heparin-responsive stem cells in cultures of adult forebrain, similar to what we reported earlier with EGF-stimulated adult forebrain stem cells (Reynolds and Weiss, 1992). When we compared the generation of thoracic spinal cord stem cell-generated spheres in the two growth factor combinations, e.g., EGF+bFGF versus bFGF+heparin, we found that both conditions produced similar expandable, multipotential spheres (C. Dunne and S. Weiss, unpublished observations). Considering the observation that EGF alone gives no spheres and bFGF alone gives very small spheres that cannot expand, we propose the following. Our working hypothesis is that primary thoracic spinal cord stem cell division is stimulated by activation of the bFGF receptor. Adequate heparin, likely in its proteoglycan form, is present on the primary cells to support proliferation (Spivak-Kroizman et al., 1994) in the absence of any added in culture. The proliferation of secondary stem cells can be stimulated by either bFGF (requiring heparin) or EGF. In support of this hypothesis are preliminary results whereby primary 8-d-old spheres generated in either EGF+bFGF or $\mathrm{bFGF}+$ heparin were successfully subcloned in EGF alone (C. Dunne and S. Weiss, unpublished observations).

Given the model proposed above for thoracic spinal cord stem cells and noting the in vitro response of forebrain stem cells to EGF alone (Reynolds and Weiss, 1992; this study), it seems plausible to conclude that the primary stem cells isolated from the lateral ventricles and spinal cord differ in their response to growth factors. Might this be related to different mitotic activities within these distinct adult CNS regions? As outlined in the introduction, the principal region of mitotic activity in the adult brain is the subepedymal cell layer of the lateral ventricles (Smart, 1961; Morshead and van der Kooy, 1992). Other than the subependyma, only the central canal (ependyma) of the spinal cord has been demonstrated to exhibit significant mitotic activity (relative to any other ventricles) in the adult (Adrian and Walker, 1962; KrausRuppert et al., 1975). These mitotic activities, however, differ remarkably with respect to the location and number of cells, normal fate of the progeny, and response to injury. First, in the lateral ventricles, the vast majority of significant constitutive proliferation is within the subependyma (Smart, 1961; Morshead and van der Kooy, 1992), whereas in the spinal cord it is the ependyma of the central canal and not the subependyma that contains most, albeit few in number, of the mitotically active cells (Adrian and Walker, 1962). Moreover, even within the ependyma, the labeling index for the central canal was $8 \%$, whereas that of the forebrain lateral ventricles was 22\% (Kraus-Ruppert et al., 1975). Second, although Lois and Alvarez-Buylla (1994) convincingly demonstrated that mitotically active cells of the subependyma migrate rostrally to the olfactory bulb to produce new neurons, previous studies of the spinal cord found no evidence for new neurons or for migration of the mitotically active cells of the ependyma (Adrian and Walker, 1962). Finally, it is interesting to note how these two mitotically active regions respond to injury. When the striatal parenchyma adjacent to the lateral ventricles is injured by a kainic acid lesion or a knife cut, there is an increase in mitotic activity in the subependyma, but no new cells migrate into the injured areas (Morshead and van der Kooy, 1992) (D. van der Kooy, personal communications). On the other hand, Frisen and colleagues (1995) recently showed that after laminectomy, new astrocytes appear to migrate from a region adjacent to the central canal to contribute to the glial scar. These authors concluded that a progenitor or stem cell population may indeed be present near or in the central canal, which can be identified by nestin expression, and it is this population that is mobilized and recruited to injury sites as part of the formation of the glial scar. In summary, the mitotic activities of the lateral ventricles/subependyma and central canal differ in many respects. Thus, it is plausible that two populations of stem cells, which clearly subserve at least two 
distinct functions in the adult in vivo, are present in the lateral ventricles and spinal cord, respectively. Consequently, when they are isolated in vitro, it is perhaps not unexpected that these two populations respond differently to growth factors.

In addition to those issues discussed above, at least three additional questions remain unanswered, the latter two specifically regarding the stem cells isolated from the adult spinal cord. (1) How do our findings relate to those of Palmer and colleagues (1995), who have generated bFGF-dependent longterm cultures of neuronal and glial progenitors from both ventricular and nonventricular adult brain regions? It is possible that different culture conditions by Palmer et al. (1995), e.g., use of serum and higher concentrations of bFGF, may allow for stimulation of growth from nonventricular regions, something we never observed in our cultures whether $\mathrm{EGF}+\mathrm{bFGF}$ or $\mathrm{bFGF}+$ heparin was used. It is difficult to compare the exact nature of the cells that respond in the bFGF-dependent cultures, because clonal analyses were not performed; however, we concur with the authors' speculation that one difference between the ventricular and nonventricular zone might be the primitive nature of the cells. Thus, the ventricular zones likely contain the most primitive stem-like cells, those isolated in our study. The nonventricular zones (parenchyma) may contain more restricted progenitors, many of which may require more complex signaling to be mobilized. (2) Do the spinal cord stem cells have the potential to produce motor neurons? Although Gritti et al. (1996) report the presence of ChAT-immunoreactive neurons in cultures of forebrain stem cell progeny, we have yet to observe such neurons in any of our spinal cord stem cell progeny cultures. The culture conditions, e.g., presence of additional factors, may influence these expressions. In fact, the continued presence of EGF + bFGF likely underlies the low yield of differentiated cells, in comparison to that observed by Gritti and colleagues (1996). They suggest that removal of the mitogen allows for enhanced differentiation. It is noteworthy, however, that the addition of serum to plated adult forebrain spheres does not enhance neuronal differentiation, as was the case for embryonic stem cell progeny (Vescovi et al., 1993; Reynolds and Weiss, 1996), but seems to attenuate the process (C. Dunne and S. Weiss, unpublished observations). (3) To what extent do these findings in the mouse spinal cord extend to higher mammals? There are preliminary meeting reports of human equivalents to the embryonic stem cells that have been isolated and propagated in cell culture (Cattaneo et al., 1995). In addition, preliminary studies suggest that neural stem cells, which respond to EGF+bFGF, are present in the adult primate forebrain and spinal cord (S. Weiss, unpublished observations).

The presence of neural stem cells in the adult spinal cord and in the third and fourth ventricles raises some interesting practical considerations. In addition to putative roles in continued histogenesis of the adult CNS (to be determined), these cells may be amenable to modification and manipulation. Recently, Craig and co-workers (1996) demonstrated that infusion of EGF into the lateral ventricles resulted in enhanced proliferation of cells in the subependymal layer. Moreover, the cells migrated laterally and medially, in contrast to their normally circumscribed route along the rostral-caudal ventricular axis. Six to nine weeks after removal of the mitogen, new neurons and glia were observed in the striatal parenchyma. Thus, neural stem cells may be mobilized in vivo, and new neurons and glia can be delivered to sites within the mature CNS. It is reasonable to conclude from the results of the present study that such mobilizations may be possible in other regions of the mature CNS, such as the spinal cord. In particular, when speculating about their putative endogenous propensity to produce glia, one can envisage manipulating spinal cord stem cells in two different circumstances. The relative numbers of oligodendroglia and astrocytes would be critical in maintaining normal myelination in demyelinating conditions. In addition, the glial microenvironment may be modified after axotomy, to allow for enhanced regrowth. Additional studies aimed at understanding the endogenous in vivo properties of spinal cord neural stem cells, coupled with identification of the signaling molecules that direct the generation of specific lineages in vitro, will serve to guide the development of such strategies.

\section{REFERENCES}

Adrian Jr EK, Walker BE (1962) Incorporation of thymidine- $\mathrm{H}^{3}$ by cells in normal and injured mouse spinal cord. J Neuropathol Exp Neurol 21:597-609.

Ahmed S, Reynolds BA, Weiss S (1995) BDNF enhances the differentiation but not the survival of CNS stem cell-derived neuronal precursors. J Neurosci 15:5765-5778.

Altman J (1963) Autoradiographic investigation of cell proliferation in the brains of rats and cats. Anat Rec 145:573-591.

Altman J, Das GD (1965) Autoradiographic and histological evidence of postnatal hippocampal neurogenesis in rats. $\mathbf{J}$ Comp Neurol 124:319-335.

Bayer SA, Yackel JW, Puri PS (1982) Neurons in the rat dentate gyrus granular layer substantially increase during juvenile and adult life. Science 216:890-892.

Bogler O, Wren D, Barnett SC, Land H, Noble M (1990) Cooperation between two growth factors promotes extended self-renewal and inhibits differentiation of oligodendrocyte-type- 2 astrocyte (O-2A) progenitor cells. Proc Natl Acad Sci USA 87:6368-6372.

Bruni JE, Del Bigio MR, Clattenburg RE (1985) Ependyma: normal and pathological. A review of the literature. Brain Res Rev 9:1-19.

Cameron HA, Woolley CS, McEwen BS, Gould E (1993) Differentiation of newly born neurons and glia in the dentate gyrus of the adult rat. Neuroscience 56:337-344.

Cattaneo E, Magrassi L, Galli R, Frolichstal P, Pezzotta S, Butti G, Govoni S, Vescovi AL (1995) Non-transformed human stem cell lines survive and integrate upon transplantation into the embryonic rat brain. Soc Neurosci Abstr 21:796.9.

Chauhan AN, Lewis PD (1979) A quantitative study of cell proliferation in ependyma and choroid plexus in the postnatal rat brain. Neuropathol Appl Neurobiol 5:303-309.

Craig CC, Tropepe V, Morshead CM, Reynolds BA, Weiss S, van der Kooy D (1996) In vivo growth factor expansion of endogenous subependymal neural precursor cell populations in the adult mammalian brain. J Neurosci 16:2649-2658.

Frisen J, Johansson CB, Torok C, Risling M, Lendahl U (1995) Rapid, widespread and long-lasting induction of nestin contributes to the generation of glial scar tissue after CNS injury. J Cell Biol 131: 453-464.

Gritti A, Parati EA, Cova L, Frolichstall P, Galli R, Wanke E, Faravelli L, Morassutti DJ, Roisen F, Nickel DD, Vescovi AL (1996) Multipotential stem cells from the adult mouse brain proliferate and self-renew in response to basic fibroblast growth factor. J Neurosci 16:1091-1100.

Hall PA, Watt FM (1989) Stem cells: the generation and maintenance of cellular diversity. Development 106:619-633.

Korr H (1980) Proliferation of different cell types in the brain. Adv Anat Embryol Cell Biol 61:1-72.

Kraus-Ruppert R, Laissue J, Burki H, Odartchenko N (1975) Kinetic studies on glial, Schwann and capsular cells labelled with $\left[{ }^{3} \mathrm{H}\right]$ thymidine in cerebrospinal tissue of young mice. J Neurol Sci 26:555-563.

Lois C, Alvarez-Buylla A (1993) Proliferating subventricular zone cells in the adult mammalian forebrain can differentiate into neurons and glia. Proc Natl Acad Sci USA 90:2074-2077.

Lois C, Alvarez-Buylla A (1994) Long distance neuronal migration in the adult mammalian brain. Science 264:1145-1148. 
Luskin M (1993) Restricted proliferation and migration of postnatally generated neurons derived from the forebrain subventricular zone. Neuron 11:173-189.

Matsui Y, Zsebo K, Hogan BL (1992) Derivation of pluripotential embryonic stem cells from murine primordial germ cells in culture. Cell 70:841-847.

Morshead CM, van der Kooy D (1992) Postmitotic death is the fate of constitutively proliferating cells in the subependymal layer of the adult brain. J Neurosci 12:249-256.

Morshead CM, Reynolds BA, Craig CG, McBurney MW, Staines WA, Morassutti D, Weiss S, van der Kooy D (1994) Neural stem cells in the adult mammalian forebrain: a relatively quiescent subpopulation of subependymal cells. Neuron 13:1071-1082.

Palmer TD, Ray J, Gage FH (1995) FGF-2-responsive neuronal progenitors reside in the proliferative and quiescent regions of the adult rodent brain. Mol Cell Neurosci 6:474-486.

Potten CS, Loeffler M (1990) Stem cells: attributes, cycles, spirals, pitfalls and uncertainties. Lessons for and from the crypt. Development 110:1001-1020.

Ray J, Gage FH (1994) Spinal cord neuroblasts proliferate in response to basic fibroblast growth factor. J Neurosci 14:3548-3564.

Reynolds BA, Weiss S (1992) Generation of neurons and astrocytes from isolated cells of the adult mammalian central nervous system. Science 255:1707-1710.
Reynolds BA, Weiss S (1993) EGF-responsive stem cells in the mammalian central nervous system. In: Neuronal cell death and repair (Cuello AC, ed), pp 247-255. Amsterdam: Elsevier.

Reynolds BA, Weiss S (1996) Clonal and populations analyses demonstrate that an EGF-responsive mammalian embryonic precursor is a stem cell. Dev Biol 175:1-13.

Reynolds BA, Tetzlaff W, Weiss S (1992) A multipotent EGF- responsive striatal embryonic progenitor cell produces neurons and astrocytes. J Neurosci 12:4565-4574.

Smart I (1961) The subependymal layer of the mouse brain and its cell production as shown by radioautography after thymidine- $\mathrm{H}^{3}$ injection. J Comp Neurol 116:325-338.

Spivak-Kroizman T, Lemmon MA, Dikic I, Laidbury JE, Pinchasi D, Huang J, Jaye M, Crumley G, Schlessinger J, Lax I (1994) Heparininduced oligomerization of FGF molecules is responsible for FGF receptor dimerization, activation, and cell proliferation. Cell 79:1015-1024.

Vescovi A, Reynolds BA, Fraser DD, Weiss S (1993) Basic fibroblast growth factor regulates the proliferative fate of both unipotent (neuronal and bipotent neuronal/astroglial) epidermal growth factorgenerated progenitor cells. Neuron 11:951-966.

Weiss S, Reynolds BA, Vescovi AL, Morshead C, Craig CM, van der Kooy D (1996) Is there a neural stem cell in the mammalian forebrain? Trends Neurosci 19:387-393. 